Australian Journal of

Crop Science

AJCS 13(05):753-760 (2019)

AJCS

doi: 10.21475/ajcs.19.13.05.p1491

ISSN:1835-2707

\title{
Effects of planting beds, nutrient treatment and drought stress on biochemical properties and vegetative traits of common evening primrose (Oenothera biennis L.) seeds
}

\author{
Robabeh Asghari
}

Plant Production Department, Imam Khomeini Higher Education Center, Agricultural Research, Iran

*Corresponding author: fariba2022@yahoo.com

\begin{abstract}
Oenothera biennis (Common Evening-Primrose, Evening Star, or Sun Drop) is an ornamental plant with medicinal properties belonging to the Onagraceae-Oenotheraceae family and native to North America. Evening primrose seed oil is used to deal with fat accumulation in the body, diabetes, premenstrual syndrome and other diseases, including eczema, mastalgia, cancer, multiple sclerosis and rheumatism. Recent studies have confirmed the presence of antioxidant activity in the polyphenols in evening primrose seeds. In order to evaluate the effect of different planting beds, organic fertilizers and drought stress, as the evening primrose's environmental and nutritional factors in growth and phytochemical properties, this experiment was carried out at the department of plant products research greenhouse in 2017. The experiment was performed using a completely randomized design in 4 treatments and with three replications. Seeds were planted in the prepared beds. Seedlings resulted from seeding and germination of seeds were transferred to different planting media. Growth characteristics were studied at the end of the plant growth period and before their flowering, and the ripe seeds after harvesting were used to measure 100 seed weight and biochemical traits. The results were analyzed statistically using one-way ANOVA. Also, simple correlation coefficients were calculated to obtain the ratio of characteristics with each other by Duncan's method.
\end{abstract}

Keywords: Common evening primrose; Planting media; Biochemical properties; Vermicompost; Fatty acid.

Introduction

Common evening primrose is an ornamental plant with medicinal properties, belonging to the family OnagraceaeOenotheraceae and native to North America (Hall, et al., 1988). This plant is biennial with fluffy surface, a height of 0.5-1.5 meters, alternate yellow leaves with toothed margins and fruit capsule containing 200-650 seeds. Its seeds contain a kind of oil that the medicinal properties of this plant are due to the presence of this active ingredient, gamma-linoleic acid (Bordonaba and Terry, 2008; Ghasemnezhad, 2007; Gholinezhad, et al., 2008; Ide, 1988). This fatty acid is an important mediator in human metabolism and prostaglandins synthesis.

Epidemiological studies have shown that the consumption of foods containing phytochemicals plays a very important role in maintaining the health of the body. Among phytochemicals, polyphenols have significant health effects in the body. These compounds, due to their antioxidant activity, can under oxidative stress conditions reduce the oxidation of macromolecules in the body's cells and consequently reduce the risk of oxidative stress such as cancer, cardiovascular diseases and diabetes. Phenolic compounds, in addition to their role in biological systems, along with preventing the oxidation process inhibit changes in taste, color, and reduce nutritional value and safety of oils and fats, as well as products containing lipid compounds (Singh, et al., 2007). The antioxidant properties of these compounds are mainly due to their resuscitation power and chemical structure, which they can neutralize free radicals, form complex with metal ions, and disable single and triple oxygen molecules (Ahmadi, et al., 2007). In recent years, with increasing awareness about the benefits of using antioxidant properties and the willingness of producers and consumers to produce natural products, many studies have been done to find the richest sources of natural antioxidants (Gülçin et al., 2003). Studies have shown that plants as rich sources of antioxidant compounds contain significant amounts of phenolic compounds, such as phenolic acids, flavonoids, tannins and phenolic diterpenes (Shahidi, 1997). These compounds also have significant antimicrobial effects. For this reason, today, the use of a wide range of plants, especially medicinal plants, has been considered by researchers (Kulisic, et al., 2004).

Using vegetable oils in traditional medicine is very common and they are used in the treatment of physiological diseases and prevention of infection ( $\mathrm{Hu}$, et al., 2015). Evening primrose seed oil is used to deal with fat accumulation in the body, diabetes, premenstrual syndrome (PMS), and other diseases, 
including eczema, mastalgia, cancer, multiple sclerosis, rheumatism, and high levels of cholesterol (Aitani, et al., 2003; Deng, et al., 2001; Sekeroglu and Ozguven, 2006). Although compared to the oil of this plant, the existence of other compounds in it has been underestimated, recent studies have confirmed the presence of antioxidant activity in the polyphenols in evening primrose seeds (Balasinska, B. and Troszynska, 1998; Birch, et al., 2002; Kulkarni and Deshpande, 2007; Wettasinghe, et al., 2002; Wettasinghe, et al., 1999; Wettasinghe, et al., 2000). Today, the role of inhibitory effect of plant polyphenols on glucose digestive enzymes, such as alpha glucosidase, has been considered, and a number of studies have tended to this point because the action of these enzymes during digestion and absorption of food prevents diabetes (Deguchi, et al., 2000; Golrach, et al., 2011; Honda and Hara, 1993). One of the researchers stated that because of the inhibitory effect of poly-alpha-glucosidase in guava leaf, it prevents the increase in blood glucose levels after a meal (Deguchi, et al., 2000). The presence of high concentrations of polyphenols in the evening primrose seeds extract, which was prepared from fat removed ethanolic extracts and then concentrated and dried, was confirmed. Therefore, evening primrose extract due to polyphenols and their role in inhibiting the activity of $\alpha$-glucosidase enzyme has potential ability in controlling blood glucose levels after meals (Ghasemnezhad and Honermeier, 2007; Gorlach, et al., 2011). In recent years, due to an increase in lifestyle-related diseases (cardiovascular diseases, diabetes, cancer and neurological diseases), biological activities of polyphenols have been taken into consideration (Ghasemnezhad and Honermeier, 2007; Hartzfeld, et al., 2002; Lewandowsk, et al., 2014).

From the agronomic factors that have a remarkable effect on the quantitative and qualitative yield of medicinal plants, crop density and nutrition can be mentioned. The oil content of seeds of evening primrose varies between $20-30 \%$, depending on factors such as cultivar, growth conditions and seed life span (Deng, et al., 2001). Numerous studies have focused on the effects of nutrition, plant density, genetic characteristics, planting medium, environmental stresses and other environmental conditions, including ambient temperature, on the quantity and quality of Olive oil (Aiazzi \& Di Rienzio, 2009; Alagukannan, et al., 2008; Deguchi, et al., 2000; Fricke, et al., 2006; Gholinezhad, et al., 2008; Kulkarni and Deshpande, 2007).

In order to investigate the effect of vermicompost and plant density on quantitative and qualitative properties of medicinal plant of evening primrose, a factorial experiment was conducted in a complete randomized block design with 12 treatments and 3 replications in the years 2008-2010. Treatments consisted of 4 levels of vermicompost $(0,2,3$ and $5 \mathrm{~kg} / \mathrm{m} 2$ ) and three planting densities (9, 12 and 20 plants per square meter). The results showed that increased levels of vermicompost significantly improved plant height, seed yield, oil percentage, oil yield and the refractive index of oil (Darbandi, et al., 2010).

This research was carried out with the aim of extraction of oil and phenol from evening primrose seed, measuring them and identifying the composition of fatty acids in the seed to study the effect of planting media on desired traits.

\section{Results}

Tables 1 and 2 present the means comparison results of the growing bed and water stress effects on the growth and phytochemical characteristics of evening primrose seed. Table 1 shows that the growth characteristics of the plants grown in soilless beds with vermicompost (T2) had the highest levels. The total amount of phenol in the seeds of plants grown in soil conditions is higher and the presence or absence of drought stress does not have a significant effect on phenol content. In seeds obtained from plants in different beds, there were significant changes observed in fatty acids amounts, with the exception of palmitic acid (Tables 2). Fig.1 and 2 show the relation between leaf length and root length with growing bed. Treatments T5-T9 were not suitable for seed production, so they were excluded from experiment. The result of analysis of variance of the data obtained from the research showed that the type of beds and the nutrient treatments used were significantly $(P \leq 0.01)$ effective on vegetative traits such as leaf and root length and biochemical characteristics, including fatty acids of the seed oil, excluding palmitic acid, although they did not have much effect on the weight of a hundred seeds and the amount of palmitic acid.

The amount of phenol in the seeds of plants grown in soil conditions is higher and the presence or absence of drought stress does not have a significant effect on phenol content (Fig.3).

In terms of fatty acids, with the exception of palmitic acid, in seeds obtained from plants in different beds there were significant changes observed. The T3, which is a soil bed type, provides better conditions for the production of stearic and arachidonic from saturated fatty acids group, and fatty acids, which have been found to be present in a small amount in the seed of the plant and are referred to as others (Table 2 and Fig.4).

Oleic acid also has the highest percentage in the soil bed under drought stress. Although stearic acid in these conditions (T4) shows a larger amount, but the difference is not significant (Fig.5).

Linoleic and gamma-linoleic acids are higher in soilless beds. Although the amount of gamma-linoleic acid in the T1 that has a soilless bed is highest, in the next place is the $T 3$, which has a soil bed and is subject to drought stress (Fig.6).

\section{Discussion}

As mentioned before, plants in only four out of nine types of plant beds produced flowers and seeds. The results of the measurements on the seeds obtained from these plants were analyzed statistically. As the results of the analysis of variance of the data obtained from the present study showed, the type of plant bed used and the dietary treatments applied were significantly effective $(P<0.01)$ on vegetative characteristics such as leaf and root length and biochemical traits, including fatty acids of the seed oil, except palmitic acid, while on the weight of 100 seeds and palmitic acid amount has not had much effect (Table 1). 
Table 1. Means comparison results of the growing bed and water stress effect on the growth and some phytochemical characteristics of evening primrose seed.

\begin{tabular}{lccccc}
\hline Growing bed & Leaf length $(\mathrm{mm})$ & Root length $(\mathrm{mm})$ & $\begin{array}{c}100 \text { seeds weight } \\
(\mathrm{g})\end{array}$ & $\begin{array}{c}\text { Total phenol } \\
(\mathrm{mg} / \mathrm{g} \mathrm{DW})\end{array}$ & $\begin{array}{c}\text { Palmitic } \\
(\%)\end{array}$ \\
\hline 1 & & & $0.68^{\mathrm{a}}$ & $851.1^{\mathrm{c}}$ & $6.75^{\mathrm{a}}$ \\
2 & $15.0^{\mathrm{b}}$ & $8.0^{\mathrm{b}}$ & $0.70^{\mathrm{a}}$ & $917.5^{\mathrm{b}}$ & $6.72^{\mathrm{a}}$ \\
3 & $20.0^{\mathrm{a}}$ & $17.5^{\mathrm{a}}$ & $0.63^{\mathrm{a}}$ & $998.2^{\mathrm{a}}$ & $6.63^{\mathrm{a}}$ \\
4 & $15.0^{\mathrm{b}}$ & $10.0^{\mathrm{b}}$ & $0.60^{\mathrm{a}}$ & $983.6^{\mathrm{a}}$ & $6.71^{\mathrm{a}}$ \\
\hline
\end{tabular}

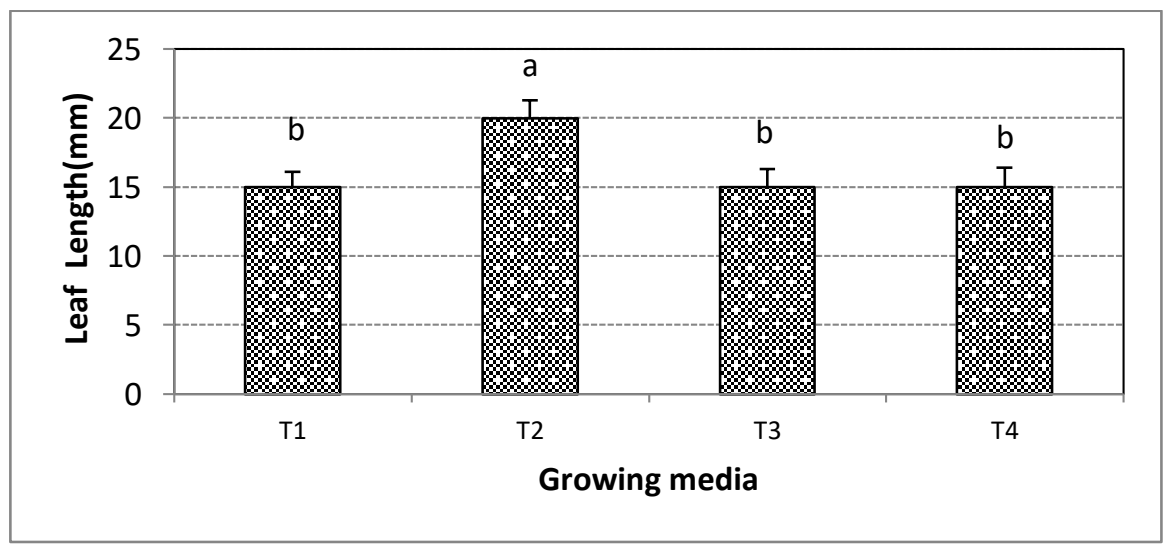

Fig 1. Relation between leaf length and growing bed.

Table 2. Means comparison results of the growing bed and water stress effect on the phytochemical characteristics of evening primrose seed.

\begin{tabular}{|c|c|c|c|c|c|c|}
\hline Growing bed & $\begin{array}{l}\text { Stearic } \\
(\%)\end{array}$ & $\begin{array}{l}\text { Oleic } \\
(\%)\end{array}$ & $\begin{array}{l}\text { Linoleic } \\
(\%)\end{array}$ & Gamma-Linolenic (\%) & $\begin{array}{l}\text { Arachidonic } \\
\text { (\%) }\end{array}$ & $\begin{array}{l}\text { Others } \\
(\%)\end{array}$ \\
\hline 1 & $1.84^{b}$ & $19.8^{\mathrm{c}}$ & $66.5^{\mathrm{a}}$ & $4.58^{a}$ & $0.31^{b}$ & $0.25^{\mathrm{c}}$ \\
\hline 2 & $1.91^{b}$ & $19.0^{c}$ & $67.5^{\mathrm{a}}$ & $4.21^{b}$ & $0.37^{b}$ & $0.34^{b}$ \\
\hline 3 & $1.80^{\mathrm{a}}$ & $21.5^{b}$ & $64.4^{b}$ & $4.39^{\mathrm{ab}}$ & $0.78^{a}$ & $0.66^{\mathrm{a}}$ \\
\hline 4 & $2.25^{\mathrm{a}}$ & $24.7^{\mathrm{a}}$ & $62 / 9^{c}$ & $3.36^{c}$ & $0.34^{a}$ & $0.18^{d}$ \\
\hline
\end{tabular}

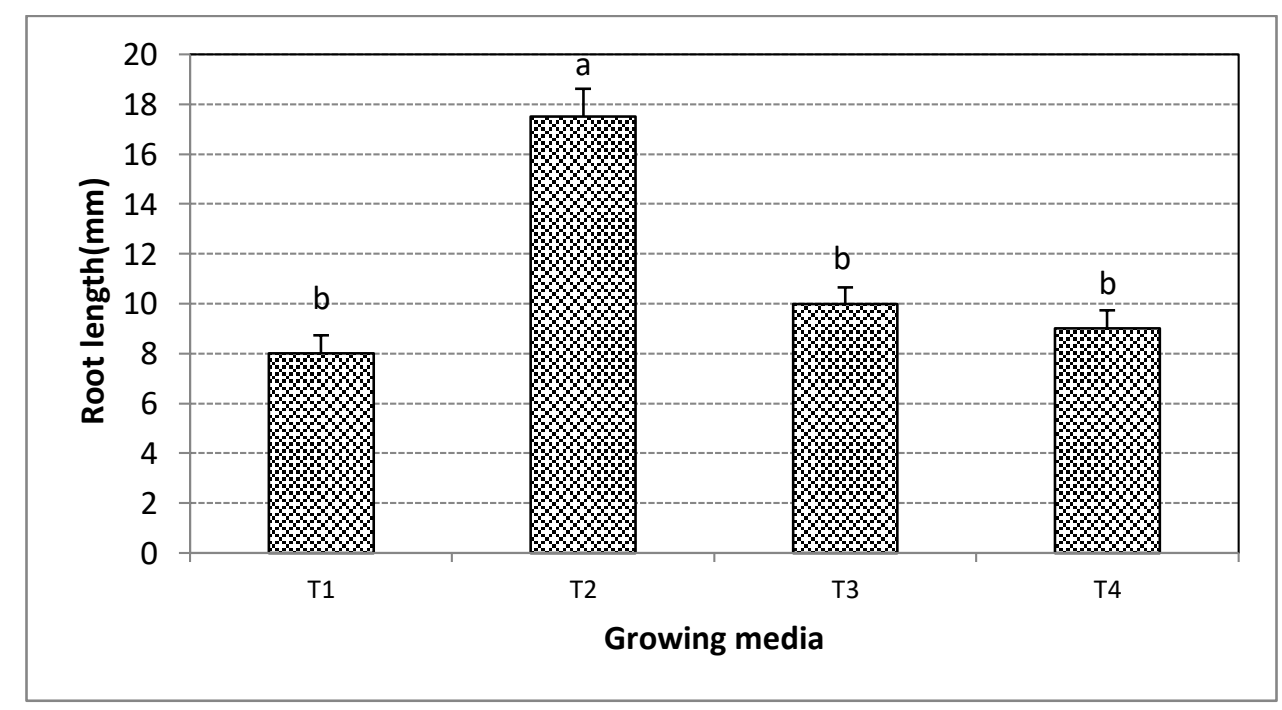

Fig 2. Relation between root length and growing bed. 
Table 3. Ingredients of organic vermicompost fertilizer.

Organic fertilizer

\begin{tabular}{llllllllllll} 
Composition & $\mathrm{Mg}(\%)$ & $\mathrm{Ca}(\%)$ & $\mathrm{N} \%$ & $\mathrm{P}(\%)$ & $\mathrm{Fe}(\mathrm{ppm})$ & $\mathrm{Zn}(\mathrm{ppm})$ & $\mathrm{Mn}(\mathrm{ppm})$ & $\mathrm{K}(\%)$ & $\mathrm{Na}(\%)$ & $\mathrm{EC}(\mu \mathrm{s} / \mathrm{cm})$ & $\mathrm{pH}$ \\
\hline Vermicompost & 0.334 & 0.44 & 0.046 & 0.298 & 89.045 & 343.35 & 67.38 & 6.125 & 0.072 & 2200 & 6.95 \\
\hline
\end{tabular}

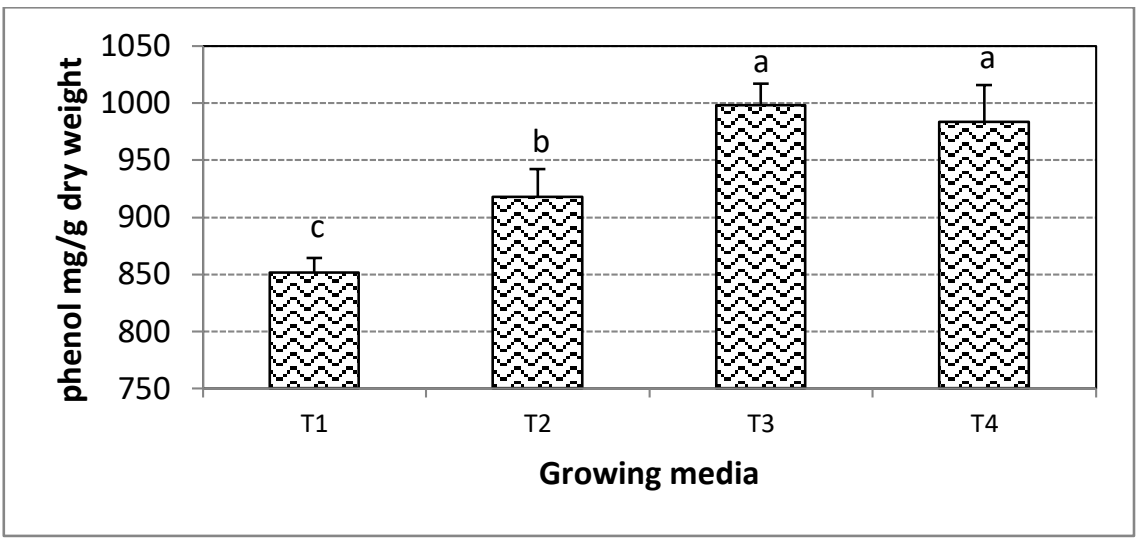

Fig 3. Phenol and growing bed relationship.

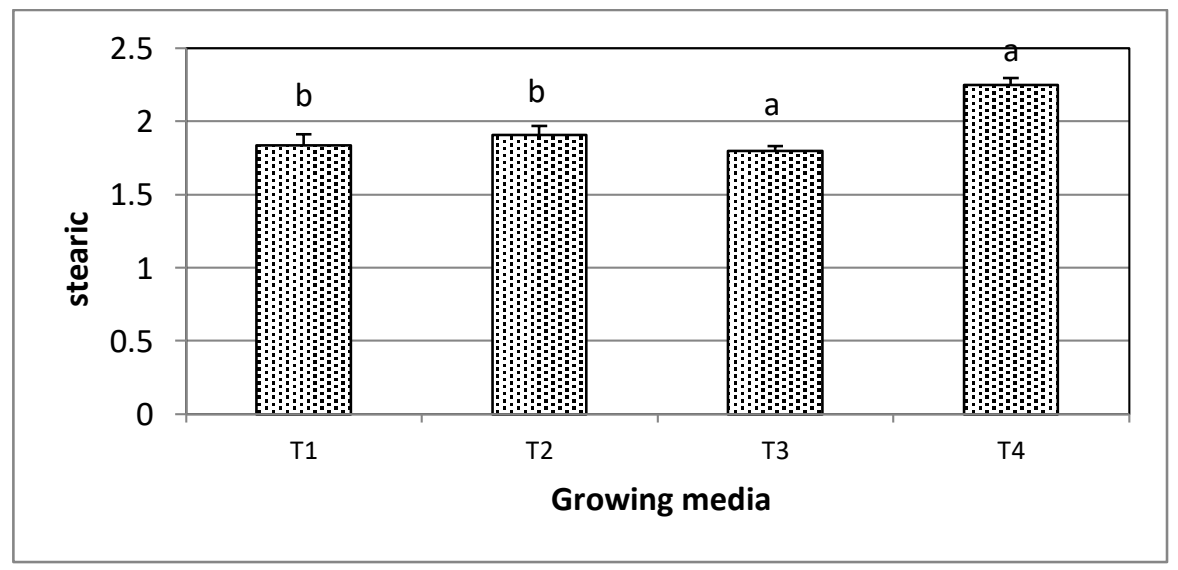

Fig 4. Stearic acid and growing bed relationship.

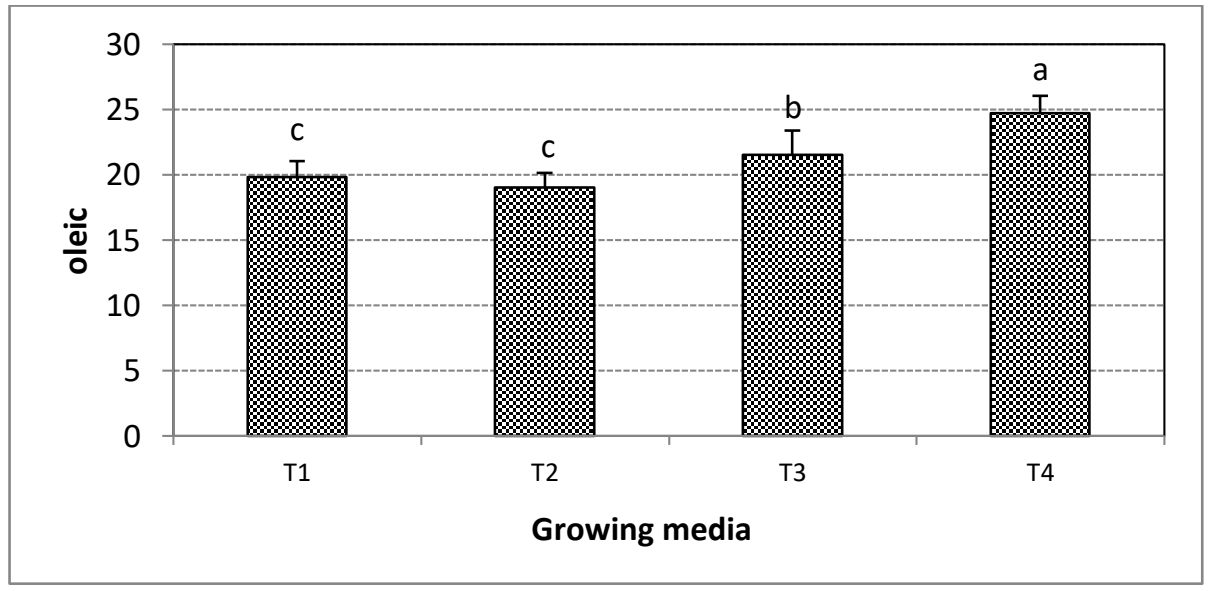

Fig 5. Oleic acid and growing bed relationship. 


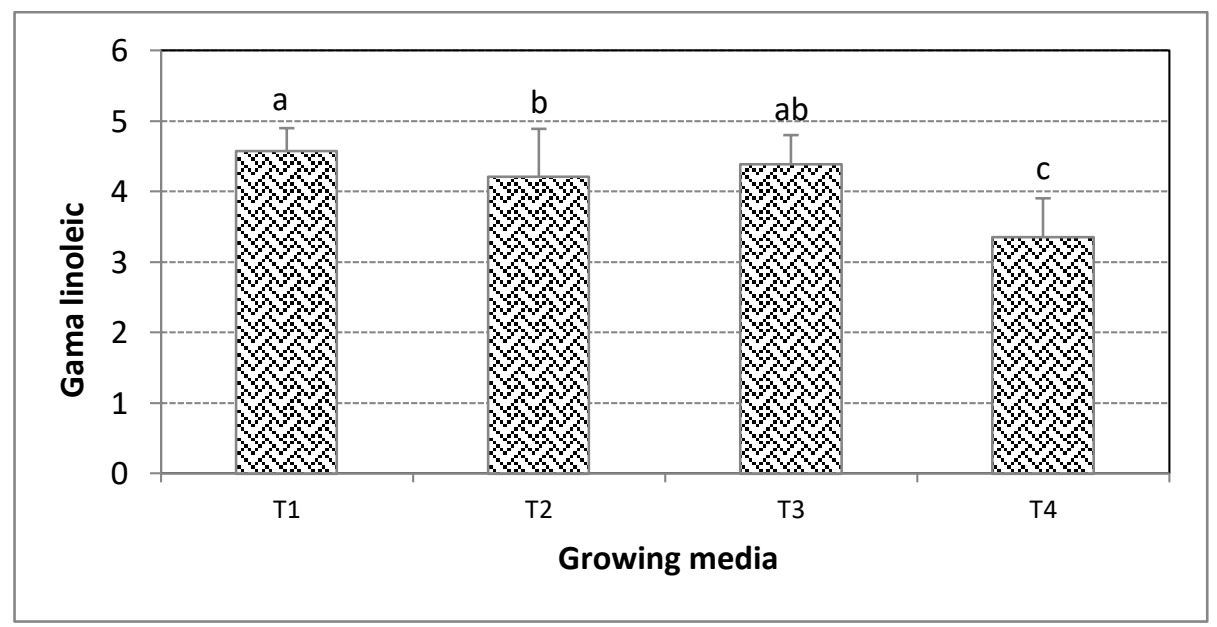

Fig 6. Gama linoleic acid and growing bed relationship.

The kind of secondary metabolites is under the genes control, but their amount, concentration and accumulation are remarkably controlled by environmental conditions (Omidbaiqi, 2009). Agronomic factors also affect quantitative and qualitative yield of medicinal plants (Aiazzi and Di Rienzio, 2009).

Considering that the physical and chemical properties of humic acid in vermicompost increase the nitrogen accumulation by the plant, it is not unexpected that the amount of oil decreases with increasing levels of vermicompost, because by increasing nitrogen content, the formation of nitrogenous protein foregrounds can be increased. Therefore, the formation of protein in the production of photosynthetic materials is increased and as a result, the amount of available material for the synthesis of fatty acids is decreased (Aitani, et al, 2003).

Salehi et al. (2011) using different levels of vermicompost on German chamomile, expressed the increase in essential oil percentage and its yield in accordance with increasing the level of this fertilizer, and stated that with increasing vermicompost content, in addition to increasing the required nutrients, the physical conditions and vital processes of soil are improved and a suitable bed for root growth is provided, that increases the production of dry matter, flower yield and essential oil content. Of course, high growth rates of the plant in the vermicompost medium confirm this. The results of this study also suggest the same fact. As shown in Table 1, in medium 2 containing vermicompost, the indices representing growth characteristics of the plant are highest. In some planting beds the plants did not flower at all and did not produce seed.

The physicochemical properties of oil can be directly affected by the combination of fatty acids, triacylglycerols and oil composition, which varies depending on the variety of seeds and some factors such as climatic conditions and soil type (Ogunniyi, 2006).

The main components derived from evening primrose oil analysis, in other words, the composition of its fatty acids have been reported in various experiments (court, 1993; Duan 1990; Hudson, 1984). The results of the analysis carried out in this study also indicate the similarity of the fatty acid composition of the evening primrose oil with the results of previous experiments. Previous reports indicate variation in the amount of linoleic acid affected by environmental factors (Deng et al., 2001; Sekeroglu and Ozguven, 2006). Also, Reiner et al. (1989) in Turkey reported the highest amount of linoleic acid in evening primrose oil from control plots (without nitrogen fertilizer) and the lowest row spacings. They suggested that the difference in weather conditions between years and the differences in performance could affect the amount of linoleic acid.

Factors such as varieties, soil, climatic conditions, and plant factors affect the composition of fatty acids in vegetable oils (Birch et al., 2002; Ogunniyi, 2006). Plant nutrition and planting density are factors that regulate the balance between the environment and genetic characteristics of the plant. There are very complex relationships between them, with the quantity and quality of the active ingredients, that rely on multiple genetic, agronomic, climatic and soil factors, and It is not simply possible to find out how this relationship is (Sarmadnia and Kucheki, 1989). In many oil products, the unsaturated fatty acids composition of the seed oil is inversely proportional to the temperature prevailing during seed maturation (Canvin, 1965). In the spring experiments, the highest amount of gamma linolenic acid in the evening primrose oil was recorded during the first harvesting time (when the capsules were green), and during the other harvesting periods, the amount of gamma linolenic acid decreased. The reason for this decline may not be directly related to the seed development duration or weather conditions at this time, and Perhaps the cause was the amount of gamma-linolenic acid and other fatty acids such as linoleic acid and oleic acid, which are synthesized prior to the gammalinolenic acid formation time. Various studies (Simon et al., 1990; Wettasinghe et al., 2002; Wettasinghe et al., 1999) showed that the temperature affects the amount of gammalinolenic acid and its reduction leads to an increase in this fatty acid. The results of this research also show the effect of environmental factors such as culture media, nutritional treatments and irrigation levels on the amounts of components of seed oil of evening primrose and the amount of resulting phenol. Since the importance of this medicinal herb is 
related to the amount of gamma-linoleic fatty acid and phenol, therefore, taking into account both of these items, T2 is the best environment, whereas if only the gamma-linoleic acid is desired, the medium 1 is better.

\section{Materials and methods}

\section{Plant materials}

In order to evaluate the effect of different planting beds, organic fertilizers and drought stress as plant environmental and nutritional factors on growth and phytochemical characteristics of evening primrose seed, experiments were conducted in the greenhouse of Department of Plant Production of Imam Khomeini Higher Education Center in 2017.

Vermicompost used in the different planting media is presented in Table 3. Only 4 media's (1-4) plants grown from the seeds sown in 9 planting media, flowered and produced seeds. The compositions of the media were as follows:

$\mathrm{T} 1=$ Cocopeat $25 \%+$ Perlite $50 \%+$ Compost + Cow manure $25 \%$

$\mathrm{T} 2=$ Cocopeat $10 \%+$ Perlite $50 \%+$ Compost + vermicompost $40 \%$

T3= Farm soil $70 \%+$ cocopeat $10 \%+$ perlite $10 \%+$ compost + cow manure (without irrigation) $10 \%$

T4= Farm soil $70 \%+$ Cocopeat $10 \%+$ perlite $10 \%+$ Compost + cow manure $10 \%$

Seedlings resulted from seeding and germination of seeds were transferred to different planting media. Transplanting was carried out in the middle of winter and continued till midsummer and ripening of seeds. Irrigation was done on average once a week, and drought treatment was created by inhibiting the irrigation in three phases in March. Growth characteristics were studied at the end of the plant growth period and before their flowering, and the ripe seeds after harvesting were used to measure 100 seed weight and biochemical traits.

\section{Measurements}

The effects of growing beds on leaf and root length and 100seed weight as growth indices were evaluated.

\section{Total phenols}

Preparation of phenolic extracts was performed by immersion in acetone $70 \%$, ethanol $70 \%$ and methanol $70 \%$ solvents $(\mathrm{v} / \mathrm{v})$. 100 milliliters of solvent were added to $10 \mathrm{~g}$ of powder and the resulting mixture was stirred for 18 hours at ambient temperature with a mechanical agitator. After this step, each of the extracts was separated from the solid part with common filter paper. Ethanolic and methanolic extracts were first concentrated by evaporation and rotary extractor of South Korean manufactured IKA RV05 at $40^{\circ} \mathrm{C}$, and extract in acetone was concentrated with a vacuum oven (German made Memert VO200). Finally, extracts were converted into powder by a freezer dryer (South Korean Operon FDB5503) and stored in an impervious to air freezer at $-18^{\circ} \mathrm{C}$ until they were used
(Kowalski, 2009). A folin-ciocalteu reagent was used to measure total polyphenols. $0.5 \mathrm{ml}$ of this reagent was added to $0.5 \mathrm{ml}$ of the extracted distillate of the plant and gallic acid standards and then $4 \mathrm{ml}$ of $1 \mathrm{M}$ sodium carbonate was added to the resulting mixture. After 15 minutes of storage at ambient temperature, the absorbance of the samples was read at $765 \mathrm{~nm}$ by UV-Vis spectrophotometer. The results were reported as $\mathrm{mg} / \mathrm{g}$ dry weight.

\section{Total oil}

In the second half of June, the plants flowered and in early August, with the beginning of seeds ripening, the capsules were hand-picked and dried. The seeds were isolated from the capsules and transferred to a laboratory for extraction and determination of oil percent. Extraction of oil was carried out by a Soxhlet apparatus using hexane solvent at $70^{\circ} \mathrm{C}$ (Christie, 1999).Then the solvent was removed by the rotary evaporator (evaporation in vacuum) and oil content was determined.

\section{Fatty acids}

Gas chromatography was used to identify the fatty acids in the oil. Identification of the components in the oil was done with a Youngling-Acme 6000 model gas chromatography machine equipped with a BPX-70 column type which had $0.25 \mathrm{~mm}$ inner diameter and $120 \mathrm{~m}$ length, a helium gas carrier, an injector temperature of $250^{\circ} \mathrm{C}$, and FID detector type. The injection volume was $0.5 \mu \mathrm{l}$ for each sample (Christie, 1999).

\section{Statistical analysis}

Data analysis was performed using SPSS software (version 16) and Microsoft Office Excel (2007 version), and the Excel 2003 software was used to plot the graphs. Data were analyzed using one-way ANOVA in supplementary Tables 1 and 2 below. Also, simple correlation coefficients were calculated to obtain the relationship between traits with Duncan's method.

\section{Conclusion}

The medicinal property of this plant is related to the presence of gamma-linolenic acid and its phenolic compounds, and both of these compounds are produced at high levels in the T3, which is a soil bed with drought stress. Although gammalinoleic acid has the highest levels in the T1, its difference with T3 is less. Therefore, the presence of vermicompost in the medium of this plant does not necessarily have a positive effect on its active substances as a medicinal plant, but its amount, although small in soilless media, is higher than the soil bed. Therefore, due to the medicinal properties of this plant, the soil beds provide a better environment in conditions of water stress.

\section{References}

Ahmadi F, Kadivar M and Shahedi M (2007) Antioxidant activity of Kelussia odoratissima Mozaff in model and food systems. Food Chem. 105: 57-64. 
Aiazzi MT, Rienzio JA Di, Sosa $L$ (2009) Effects of different salts on the germination and early seedling growth of Atriplex cordobensis. Seed Sci Technol. 37:17-24.

Aitani M, Kimura H, Abiru Y, Soyama H, Murakami H, Li Zhang, $H$, Sugishita T and Konishi $Y$ (2003) The effect of an extract of evening-primrose seeds on postprandial blood glucose level and its active components. Japanese Society for Food Science and Technology Journal, Vol. 50, No. 4: 180 - 187.

Alagukannan G, Ganesh S, Gopal S K (2008) Characterization and screening of different ecotypes of Aloe vera for growth, yield and quality. International Aloe Science Council. Texas:302-624.

Balasinska B and Troszynska A (1998) The total antioxidative activity of evening primrose (Oenothera paradoxa) cake extract measured in vitro by liposome model and murine L1210 cells. J Agric Food Chem. 46(9):3558-3563.

Birch AE, Fenner G, Watkins R, Boyd LC (2001) Antioxidant properties of evening primrose seed extract. J Agric Food Chem. 49(9):4502-4507.

Bordonaba, J G, Terry L.A (2008) Biochemical profiling and chemometric analysis of seventeen UK-grown black currant cultivars. J Agric Food Chem. 56(16):7422-7430.

Court W A, Hendel J G, Pocs R (1993) Determination of the fatty acids and oil content of evening primrose (Oenothera biennis L). Food Res Int. 26(3):181-186.

Darbandi N, Azizi M, Aruyi H (2010) Effect of different levels of vermicompost and plant density on quantitative and qualitative characteristics of evening primrose medicinal plant, Ministry of Science, Research and Technology, Ferdowsi University of Mashhad - Faculty of Agriculture (in Persian).

Deng Y C, Hua H M, Li Jun, Lapinkase P (2001) Studies on the cultivation and uses of evening primrose (Oenothera spp.) in China. Econ Bot. 55(1):83-92.

Duan J X (1990) Introduction and cultivation of Oenothera. Plant introduction and acclimatization. 7:79-89.

Fricke W., Wei W., Alexandersson E., Miller T., Kjellbom PO., Richardson, A., Wojciechowski, T., Schreiber, L., Akhiyarova, G., Veselov, D., Kudoyarova, G., Volkov, V., 2006. The shortterm growth response of salt of the developing barley leaf. J Exp Bot. (57): 1079-1095.

Ghasemnezhad A, Honermeier B (2007) Seed yield, oil content and fatty acid composition of (Oenothera biennis L.) affected by harvest date and harvest method. Ind Crop Prod. 25:274281.

Ghasemnezhad A (2007) Investigations on the effects of harvest methods and storage conditions on yield, quality and germination of evening primrose (Oenothera biennis L.) seeds. Ph.D. thesis. Justus Liebig University, Giessen. 114:112.

Gholinezhad A, Tobeh A, Hasanzadeh ghorottapeh A, Asgari A (2008) The effect of density and planting arrangement of yield and yield components of sunflower. J Agr Sci. 18: 87-99.

Gorlach S, Wagner W, Podsedek A, Sosnowska D, Dastych J, Koziołkiewicz M (2011) Polyphenols from evening primrose (Oenothera paradoxa) defatted seeds induce apoptosis in human colon cancer $\mathrm{CaCO}_{2}$ cells. J Agr Food Chem. 59:69856997
Gülçin I, Oktay M, Kıreçcr E, Küfrevıoğlu i Ö (2003) Screening of antioxidant and antimicrobial activities of anise (Pimpinella anisum L.) seed extracts, Food Chem. 83:371-382.

Hall I, Steiner E, Threadgill P, Richard W (1988) The biology of Canadian weeds, Oenothera biennis, Can J Plant Sci.68:163173.

Hartzfeld P W, Forkner R, Hunter M D, Hagerman A E (2002) Determination of hydrolysable tannins (gallotannins and ellagitannins) after reaction with potassium iodate. J Agri Food Chem. 50:1785-1790.

Honda M, Hara Y (1993) Inhibition of rat small intestinal sucrase and $\alpha$-glucosidase activities by tea polyphenols. Biosci Biotech Bioch. 57:123-124.

Hu L, Man H, Elias P M, Man M Q (2015) Herbal medicines that benefit epidermal permeability barrier function. Dermatol Sin.33:90-95.

Hudson B J F, (1984) Evening primrose (Oenothera spp.) oil and seed. Journal of the American oil chemists' society. 61:540543.

Ide T, (1988) Metabolic adjustment function of $\gamma$-linolenic acid. Japan society for bioscience, biotechnology and agrochemistry's journal. 62:46-49.

Kowalski R (2009) Silphium L. extracts - composition and protective effect on fatty acids content in sunflower oil subjected to heating and storage. Food Chem. 112:820-830.

Kulisic T, Radonic A, Katalinic V (2004) Use of different methods for testing antioxidative of oregano essential oil, Food Chem. 85:633-640.

Kulkarni M, Deshpande U (2007) In vitro screening of tomato genotypes for drought resistance using polyethylene glycol. Afr. J. Biotech. 6(6):691-696.

Lewandowsk U, Owczarek K., Szewczyk K, Podsędek A, Koziołkiewicz M, Hrabec E (2014) The influence of the polyphenol extract from evening primrose (Oenothera paradoxa) seeds on human prostate and breast cancer cell lines. Postepy Hig Med Dosw (online), 68:110-118.

Ogunniyi, D. S., 2006. Castor oil: A vital industrial raw material. Journal Bioresource Technology, 97: 1086-1091.

Omidbaigi R, (2009) Production and processing of medicinal plant, 3rd edn. Razavi ghods astan publication. p347.

Reiner H, Ceylan A, Marquard R, (1989) Agronomic performance of evening primrose (Oenothera biennis L.) in Turkey and Germany. Eucarpia congress, Gottingen. 20:5.

Salehi A, Galavand A, sephidkon F, Asgharzadeh A, (2011) Effect of application of zeolite, microbial inoculation and vermicompost on concentrations of $\mathrm{N}, \mathrm{P}, \mathrm{K}$, Essential oil content and essential oil in organic culture of German chamomile (Matricaria chamomilla L.), Journal of study and research in Iranian medicinal and aromatic plants. 27(2):188201 (in Persian).

Sarmadnia G, Kucheki A, (1989) Physiology of crop plants. Mashhad jihad University publishers. p467 (in Persian).

Sekeroglu N, Ozguven M (2006) Effects of different nitrogen doses and row spacing applications on yield and quality of (Oenothera biennis L.) grow in irrigated lowland and nonirrigated dryland conditions. Turk journal of agriculture. 30:125-135.

Shahidi F (1997) Natural antioxidants: Chemistry, health effects and applications, AOCS Press champaign. 
Simon J E, Beaubaire N, Weller S C, Janick J (1990) Borage: A source of gamma linolenic acid. In: janick J, Simon J E (ed.), Advances in new crops. Timber Press, Portland, Oregon. p528.

Singh G, Maurya S, Delampasona, M P (2007) A comparison of chemical antioxidant and antimicrobial studies of cinnamon leaf and bark volatile oils, oleoresins and their constituents, Food Chem Toxicol. 45:1650-1661.

Wettasinghe $M$, and Shahidi $F$ (2000) Scavenging of reactive oxygen species and DPPH free radicals by extracts of borage and evening primrose meals. Food Chem. 70:17-26.
Wettasinghe M, Shahidi F, (1999) Evening primrose meal: A source of natural antioxidants and scavenger of hydrogen peroxidase and oxygen-derived free radicals. J Agri Food Chem. 47:1801-1812.

Wettasinghe M, Shahidi F, Amarowicz R, 2002. Identification and quantification of low molecular weight phenolic antioxidants in seeds of evening primrose (Oenothera biennis L.). J Agri Food Chem. 50:1267-1271. 